Wright State University

CORE Scholar

$6-1-2000$

\title{
Dissociation of Al203(0001) Substrates and the Roles of Silicon and Oxygen in N-Type Gan Thin Solid Films Grown by Gas-Source Molecular Beam Epitaxy
}

\author{
J. E. Van Nostrand
}

J. Solomon
A. Saxler
Q. H. Xie
D. C. Reynolds

See next page for additional authors

Follow this and additional works at: https://corescholar.libraries.wright.edu/physics

Part of the Physics Commons

\section{Repository Citation}

Van Nostrand, J. E., Solomon, J., Saxler, A., Xie, Q. H., Reynolds, D. C., \& Look, D. C. (2000). Dissociation of Al203(0001) Substrates and the Roles of Silicon and Oxygen in N-Type Gan Thin Solid Films Grown by Gas-Source Molecular Beam Epitaxy. Journal of Applied Physics, 87 (12), 8766-8772.

https://corescholar.libraries.wright.edu/physics/146

This Article is brought to you for free and open access by the Physics at CORE Scholar. It has been accepted for inclusion in Physics Faculty Publications by an authorized administrator of CORE Scholar. For more information, please contact library-corescholar@wright.edu. 


\section{Authors}

J. E. Van Nostrand, J. Solomon, A. Saxler, Q. H. Xie, D. C. Reynolds, and David C. Look

This article is available at CORE Scholar: https://corescholar.libraries.wright.edu/physics/146 


\title{
Dissociation of $\mathrm{Al}_{2} \mathrm{O}_{3}(000$ ) substrates and the roles of sillicon and oxygen in n-type GaN thin solid films grown by gas-source molecular beam epizaxy
}

\author{
J. E. Van Nostrand, a) J. Solomon," A. Saxler, Q.-H. Xie, D. C. Reynolds, ${ }^{\text {c) }}$ \\ and D. C. Look ${ }^{\text {) }}$ \\ Air Force Research Laboratory, Materials and Manufacturing Directorate, Wright-Patterson Air Force \\ Base, Ohio 45433
}

(Received 7 January 2000; accepted for publication 20 March 2000)

\begin{abstract}
Unintentionally doped and silicon doped GaN films prepared by molecular beam epitaxy using ammonia are investigated. Hall, secondary ion mass spectroscopy (SIMS), photoluminescence, and $x$-ray data are utilized for analysis of sources of autodoping of $\mathrm{GaN}$ epitaxial films in an effort to identify whether the $n$-type background electron concentration is of impurity origin or native defect origin. We identify and quantify an anomalous relationship between the Si doping concentration and free carrier concentration and mobility using temperature dependent Hall measurements on a series of 2.0 $\mu \mathrm{m}$-thick GaN(0001) films grown on sapphire with various Si doping concentrations. SIMS is used to identify oxygen as the origin of the excess free carriers in lightly doped and undoped GaN films. Further, the source of the oxygen is positively identified to be dissociation of the sapphire stibstrate at the nitride-sapphire interface. Dissociation of SiC at the nitride-carbide interface is also observed. Finally, SIMS is again utilized to show how Si doping can be utilized to suppress the diffusion of the oxygen into the GaN layer from the sapphire substrate. The mechanism of suppression is believed to be formation of a $\mathrm{Si}-\mathrm{O}$ bond and a grealy reduced diffusion coefficient of the subsequent Si-O complex in GaN. (C) 2000 American Institute of Physics.
\end{abstract}

[S0021-8979(00)07112-7]

\section{INTRODUCTON}

GaN is a semiconductor material that shows great promise for use in optoelectronic and electronic devices due to its large, direct band gap. In spite of considerable research efforts on the part of a large number of research groups worldwide, many of the basic properties of GaN continue to evade a precise understanding. Even so, GaN rechnology has developed steadily, at the hands of a relatively few groups, culminating in the successful demorstration of efficient biue light-emitting diodes, ${ }^{2,3}$ lasers, ${ }^{4,5}$ modulation-doped fieldeffect transistors, ${ }^{6}$ and high-electron-mobility transistors. ${ }^{7,8}$ Despite these astonishing and rapid developmental successes, many problems remain that hinder further progress. Among them is a lack of understanding of the mechanisms underying impurity incorporation, the nature of native defects, and the dependence of both of these on the thermodynamics and kinetic limitations of the GaN growth technique employed. The confusion is compounded by the lack of a commercially available native substrate. Currently, the substrate of choice for $\mathrm{GaN}$ growth is $\mathrm{Al}_{2} \mathrm{O}_{3}(0001)$ becalise of its reasonably low cost and wide availability. Unfortunately, the lateral lattice mismatch between C-plane sapphire and

a) Author to whom correspondence should be addressed. Also at: AFRL/ MLPA Blog. 620, 2241 Avionics Circle, WPAFB, OH 45433-7322; electronic mail: Joseph. VanNostrand@sn.wpatb.af.mil

b) Also at: Research Institute, Utiversity of Dayton, 300 College Park, Dayton, OH 45469.

Also ar: Semiconductor Research Center, Wright State University, Dayton, OH 45435 .
$\mathrm{GaN}$ is large (13.8\%), the themal expansion cocfficients differ greatly, and the sapphire exhibits poor thermal and no electrical conductivity. Consequently, a very high densily of structural and electrical defects often dominate ritride material electrical and optical characterization results. One nearly universal aspect of unintentionally doped GaN films grown on sapphire by any technique is a n-type background carrier concentration, being of a particulariy large magnitude in early attempts at nitride epitaxy. ${ }^{9}$ This phenomenon has been attributed to imperities such as $\mathrm{Si}$ or $\mathrm{O}$, or to native defects such as $N$ vacancies. The role of $G a$ and $N$ vacancies in coping, as well as the incorporation mechanisms of impurities must be clearly underswood if progress in wide-band gap semiconductor devices is to continue at its current pace.

The belief that autodoping in GaN is due to native defects, probably N vacancies, was first introduced by Maruska and Tietjen. ${ }^{\text {to }}$ They argued that impurity concentrations in their samples were at least two orders of magnitude lower than the electron concentration. Since that time, there have been a great deal of theoretical calculations and experimental measurements that show a high likelihood of the validity of the $\mathrm{N}$ vacancy argument. However, there has not, as yet, been an unequivocal experiment to support or discount this claim. First-principle calculations of Perlin et $a l^{11}$ and Jenkins et ll $^{12}$ suggest that the dominant donor in GaN is the $\mathrm{N}$ vacancy. Another extensive theoretica! sudy of native defects in whrtzitic GaN performed by Boguslawski et al. ${ }^{13}$ suggests that the residual donor responsibie for the $n$-type character of as-grown $\mathrm{GaN}$ is again the nitrogen vacancy. 
The work by Wetzel et al. used infrared reflection and Raman spectroscopy analyses under very large hydrostatic presstre to determine the position of the localized states in GaN with respect to the band edge. In their work, they found the free electron concentration was reuced from its atmospheric value by $97 \%$ under a hydrostatic pressure of $27 \mathrm{GPa}$, suggesting the $N$ vacancy concentration at ambient could be as high as $10^{19} \mathrm{~cm}^{-3}$. Kin er al. ${ }^{14}$ examined impurity incorporation and the nature of autodoping using Hall and secondary ion mass spectroscopy (SIMS) analysis of background impurities such as $\mathrm{Si}, \mathrm{O}$, and $\mathrm{H}$. Their findings also appeared to support the $\mathbb{N}$ vacancy as a possible cause of "auto-pl-type" doping in otherwise undoped GaN films grown by gassource molecular beam epitaxy (MBE).

There exists seemingly overwheiming evidence the residual conor concentration in native GaN is due to $\mathrm{N}$ vacancies. However, there is a substantial body of works to the contrary. Neugebauer and Van de Walle ${ }^{\text {is }}$ performed furstprinciple calculations and found the formation of $N$ vacancies in $n$-type $\mathrm{GaN}$ is energetically quite costly, and hence, highly improbable. Instead, they suggested the m-kype background is due to contaminants such as Si or O. Both Si and O are conmon impurities in metalorganic chemical vapor deposition (MOCVD) grown GaN, with Si and O coming from the quartz reactor walls, and additional $O$ due to the considerable partial pressure of water present in this growh technique in comparison to nolecular beam epitaxy. Based on detailed analysis of temperature-dependent Hall measurements, Gotz et $a l^{16}{ }^{16}$ determined the activation energy for the wo shallow donor levels in GaN to range from 12 to 17 $\mathrm{meV}$ for $\mathrm{Si}$ and 32 to $37 \mathrm{meV}$ for $\mathrm{O}$. Chung and Gersinenzon ${ }^{17}$ and Ploog and Brandt ${ }^{13}$ found the carrier concentrations increased by over an order of magnitude, while electrical and optical properties were degraded, wher oxygen was intentionally incorporated into the GaN layers. Si, on the other hand, was found by Zeng et al. ${ }^{10}$ to significanty improve the quality of GaN/AlGaN multiquantum wells grown by gas-source MRE. However, the reason for this was not clear. Finally, in the work of Boguslawski et al.,$^{13}$ although they concluded $N$ vacancies are the cause of the $n$-type background in GaN, they also pointed out the equilibrium concentration of $\mathrm{Ga}$ intersticial in Ga-rich material should be comparable to the concentration of $\mathrm{N}$ vacancies. If this were the case, the doping efficiency of the Ga vacancy, Ga interstitial, and $\mathrm{N}$ vacancy should be substantially degraded, and hence, the high $n$-type carrier concentration should not be observed.

In tits article we employ gas-source MBE using ammonia to grow undoped and Si doped GaN thin solid films on $\mathrm{Al}_{2} \mathrm{O}_{3}(000 \mathrm{i})$. We investigate the source of autodoping in otherwise undoped GaN films and the dependence of the autodoping mechanism(s) on the Si doping concentration.

\section{EXPRRIMENT}

A Varian model 360 MBE system (Serial No. 002) is used to grow the GaN films using ammonia as the nitrogen source. The chamber is pumped by one corrosive service urbomolecular pump and, during growth, two liquid nitro- gen cold fingers. Union Carbide single sids polished $\mathrm{Al}_{2} \mathrm{O}_{3}(0001) 2 \mathrm{in}$. diameler substrates are quariered, and then etched in $3: 1 \quad \mathrm{H}_{2} \mathrm{SO}_{4}: \mathrm{H}_{3} \mathrm{PO}_{4}$ at $200^{\circ} \mathrm{C}$ for $10 \mathrm{~min}$. The samples are rinsed in de-ionized water, blown dry with hiquid nitrogen boil off, and bonded to molybdenum substrate holders using a 1: In:Sn mixture at $200^{\circ} \mathrm{C}$. The InSn mixture has the advantages of the superior wetting of In and the lower vapor pressure, and subsequently increased bonding liferime at growth temperature, of the Sn.

The samples are heated to a growth temperature of $800^{\circ} \mathrm{C}$ and held at this temperature until the chamber background pressure falls below $8.0 \times 10^{-9}$ Torr. Sample temperature is monitored using an optical pyrometer operating in the range $0.9-1.1 \mu \mathrm{m}$ and using an emissivity setting of : $=0.4$ (we assume the sapphire is transparent at this wavelength). Elenental Al and Ga are supplied from standard Knudser cells at the rates of 0.125 for AlN and $0.5 \mathrm{~km} \mathrm{~h}^{-1}$ for GaN. Ammonia is delivered through a cracking gas injector with a pyrolytic boron nitride diffuser plate. The gas cracker is operated at $-50^{\circ} \mathrm{C}$ to prevent condensation of the adiabatically expanding ammonia on the cracker walls. The ammonia is delivered through a corrosive service mass flow controlier at a rate of $7.3 \mathrm{sccm}$, which corresponds to a lineof-sight bean equivalent pressure of $8.2 \times 10^{-6}$ Torr. Elemental $S i$ is also supplied from a standard Knudsen cell.

Prior to growth, the sapphire surface is exposed io ammonia for 1 min. In this time there is no apparent change in the reffection high-energy electron diffraction (RHEED) pattem from the unreconstructed $|\times|$ of the sapphire surface, and we believe little if any of the surface is converted to AIN. However, this step is necessary for a stabilization of the ammonia flux. Following the $1 \mathrm{~min}$ ammonia exposure, a $200 \AA$ AIN buffer layer is deposited at $800^{\circ} \mathrm{C}$, followed by $\sim 2.0 \mu \mathrm{m}$ nominat thickness of GaN. From cross-sectional transmission electron microscopy on several samples, we estimate the dislocation densily to consistently be -5 $\times 10^{9} \mathrm{~cm}^{-2}$ near the GaN/AIN interace, but only $3-5$ $\times 10^{8} \mathrm{~cm}^{-2}$ at the surface of the 2 - $\mu \mathrm{m}$ thick GaN fimm. During growth of the AlN layer, the $1 \times 1$ RHEED pattern shows an exchange between the $[1100]_{\text {AlN }}$ and $[11 \overline{2} 0]_{\text {sapphire, a phenomenon which has been investigated }}$ using transmission electron lattice imaging. "When Si doping is uned, both the AIN and GaN layers are doped.

Structural measurements are obtained using a Philips triple-axis diffractometer with $4 \times \mathrm{Ge}(220)$ monochromatized radiation from the $\mathrm{Cu} K_{\alpha}$ line, and cither a $0.45 \mathrm{~mm}$ slit or a channel-cut analyzer $[2 \times \mathrm{Ge}(220)]$. The excitation source for the photoluminesence measurements is a $\mathrm{Me}-\mathrm{Cd}$ laser at $325 \mathrm{~mm}$. The reflection source is a xenon lamp. The refiection is measured at approximately $15^{\circ}$ off nomal incidence. This is necessary because of the dewar arrangement and the collection optics. Photoluminescence measurements are made at $2 \mathrm{~K}$ with the sample immersed in liquid $\mathrm{He}$. The spectra are analyzed with a high-resolution $4 \mathrm{~m}$ spectrometer equipped with a Radio Corporation of America C31034 A photomuliplier whe for detection. Morphology is measured using a Digital Instruments NanoScope II atomic force microscope with $\cdots 0.3$ A height resolution. The Hall-effect measurements are conducted at room kemperature with a 
TABLE I. SIMS relative sensitivity factors for various atomic species in GaN using a $10 \mathrm{keV}$ cesium beam and $\mathrm{GaN}$ as a reference signal.

\begin{tabular}{lc}
\hline Implant specie & Relative sensitivity factors in GaN $\left(\mathrm{cm}^{-3}\right)$ \\
\hline Aluminum & $4.7 \times 10^{22}$ \\
Carbon & $2.1 \times 10^{19}$ \\
Oxygen & $5.6 \times 10^{19}$ \\
Silicon & $7.4 \times 10^{19}$ \\
\hline
\end{tabular}

magnetic field of $\pm 14 \mathrm{kG}$, the results of which are averaged. For these measurements, samples of $7 \times 7 \mathrm{~mm}^{2}$ are cut from the wafers, and ohmic metal contacts are deposited on the comers (van der Pauw geometry). STMS measurements are performed with a quadrupole-based instrument using $10 \mathrm{keV}$ cesium ions at normal incidence. Sensitivity factors for aluminum, carbon, oxygen, and silicon are obtained from implanted, unintentionally doped epitaxial GaN grown by chemical vapor deposition on sapphire. The relative sensitivity factors we determined are shown in Table I.

\section{FESULTS AND DISCUSSION}

A Bragg scan of the (0002) refiection of a 2.0-pm-thick GaN layer on a $200-\AA$ - thick AlN buffer layer on $\mathrm{Al}_{2} \mathrm{O}_{3}(0001)$ is shown in Fig. 1(a). The results for a $0.45 \mathrm{~mm}$ slit in front of the $x$-ray detector is a full width at half maximum (FWHM) of a Gaussian fit to the data of 244.8 arc sec. The dominant contribution to this FWHM is misfit dislocation relaxation of the lattice. $\mathrm{Also}$, for $\mathrm{GaN}$ on $\mathrm{Al}_{2} \mathrm{O}_{3}(0001)$, significant texture is known to occur in the form of local misorientations of the GaN $c$ axis with respect to that of the
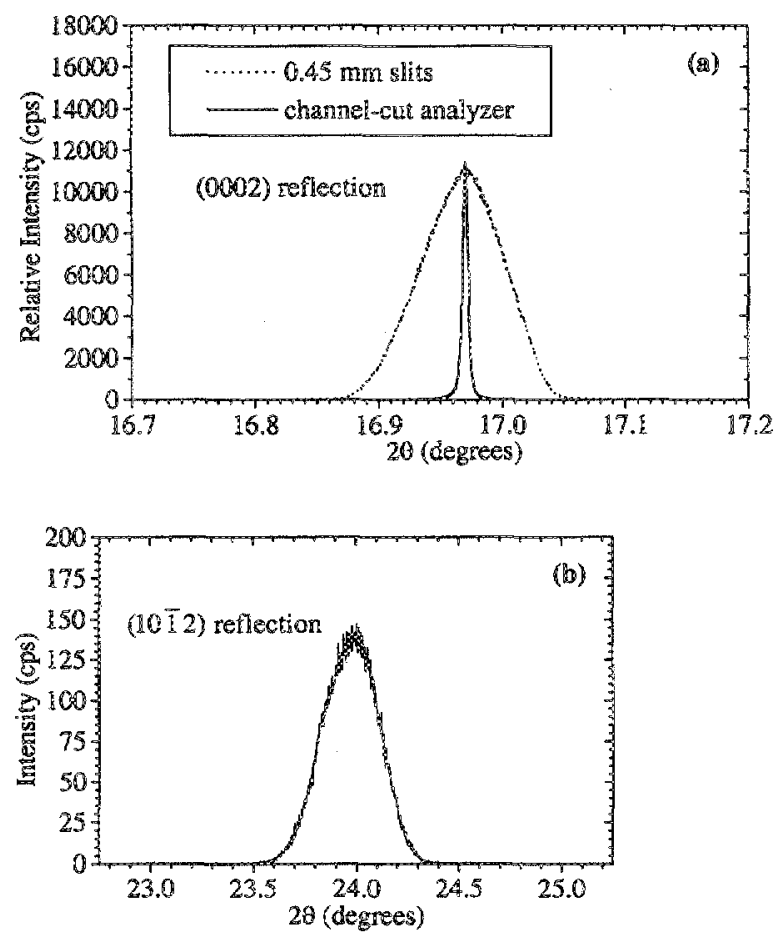

FiG. 1. Bragg scan of (a) the symmetric (0002) reflection of GaN/AN $/ \mathrm{Al}_{2} \mathrm{O}_{3}(0001)$ using a $0.45 \mathrm{~mm}$ slit in front of the detector and using a channel-cut analyzer and (b) the asymmetric reffection. Note the reduction in intensity for the asymmetric reflection.
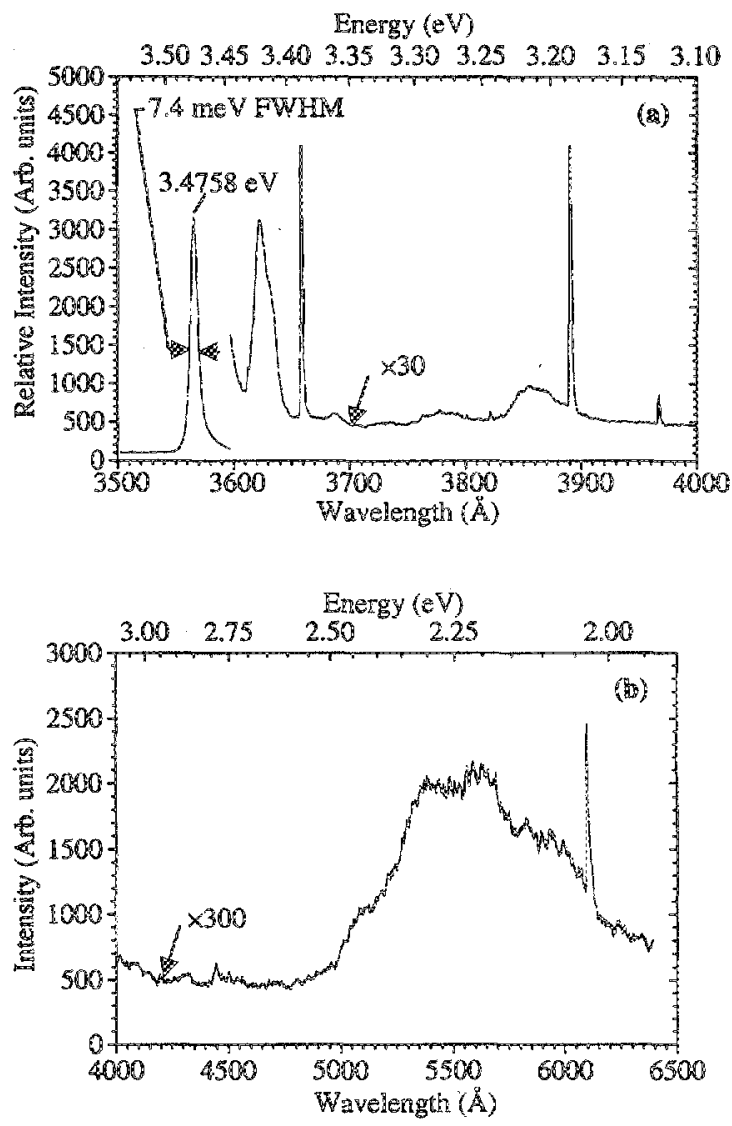

FIG. 2. Hegk-resolution photoluminescence spectra of a $2.0-$ - $u$ m-thick unintentionally foped GaN layer on an $\mathrm{A} / \mathrm{N}$ buffer on $\mathrm{Al}_{2} \mathrm{O}_{3}(0001)$. Sharp peaks are due to laser emission lines.

$\mathrm{A}_{2} \mathrm{O}_{3}(0001)$. The introduction of a channel-cut analyzer [2 $\times \operatorname{Ge}(220)]$ removes contributions to the detector signal from all but those portions of the sample whose $[0001]$ direction line up nearly exactly with that of the dominant $c$ direction, and correspondingly that of the $\mathrm{Al}_{2} \mathrm{O}_{3}(0001)$. As shown in Fig. 1(a), the results for a channel-cut analyzer in front of the detector is a FWHM of $16.9 \mathrm{src} \mathrm{sec}$ for the (0002) reflection of the $2.0-\mu m$-thick GaN film, and shows that there is very little variation in the $c$ direction of these films. This is consistent with the dislocation density described earlier. Also shown in Fig. 1 is the (10I2) asymmerric reflection of the GaN [Fig. 1(b)], having a FWHM of $\sim 990$ are sec when measured using a $0.45 \mathrm{~mm}$ sit in front of the detector. The signiticantly reduced intensity of the asymmetric reflection in comparison to the symmetric reflection is consistent with the ingh dislocation density and the considerable degree of texture exhibited by nitrides grown on sapphirc. The FWHM values for the symmetric and asymmetric peaks we show compare favorably with other pubished values for GaN films of similar thickness on sapphire.

A photoluminescence spectrum obtained at $2 \mathrm{~K}$ from a 2.2- $\mu \mathrm{m}-4$ hick unintentionally doped GaN sample is shown in Fig. 2. The dominant peak is that of the noutrat donor bound exciron. We believe the FWHM of $7.4 \mathrm{meV}$ for the neutral donor bound excion at $3.4758 \mathrm{eV}$ in this spectrum is comparable with that of other published hminescence data for GaN filans of similar thickness and carrier concentration on 

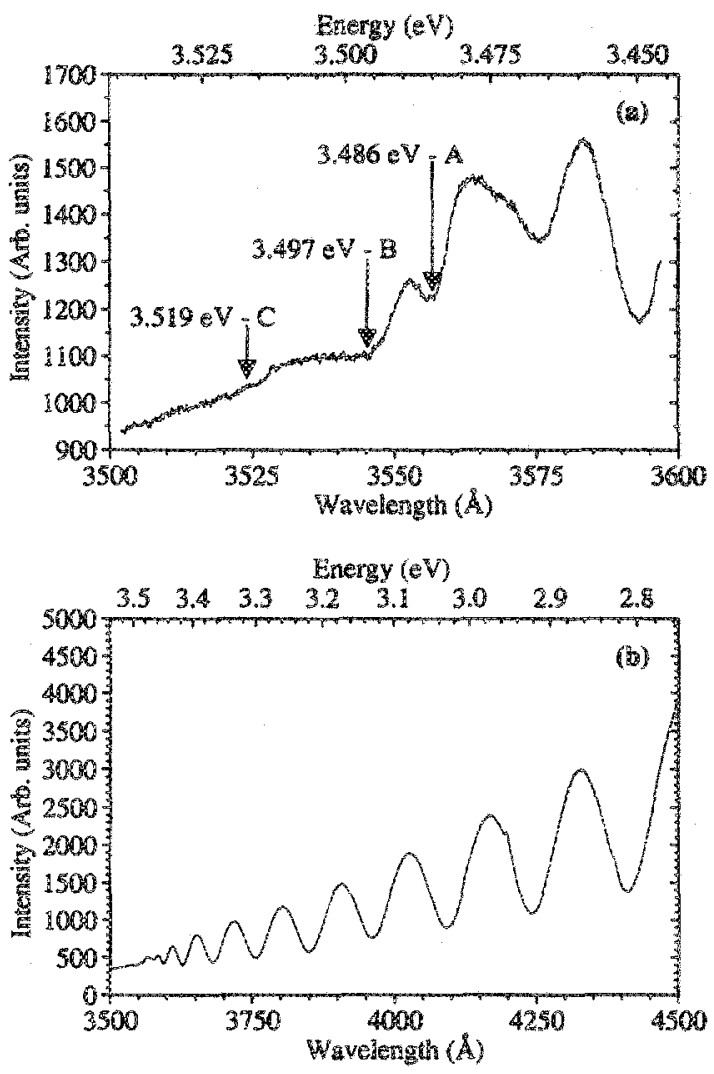

FTG. 3. High-resolution reflection spectra of a 20 - - m-lhick unintentionally doped GaN layer on an $\mathrm{AIN}$ buffer on $\mathrm{Al}_{2} \mathrm{O}_{3}(0001)$.

sapphire grown by any technique (for example, Ref. 22, and references therein). A much weaker peak at $-3.42 \mathrm{eV}$ can also be observed and is believed to be an exciton bound to a stacking fault. It is unlikely that this is a shallow donor to shallow acceptor (DAP) transition as there are no known acceptor levels that are sufficiently shallow to accommodate a DAP exciton with an energy of this size. As shown in Fig. 2(a), no other near band edge excitonic transitions can be observed in this material. Figure $2(b)$, magnified by a factor of 300 , shows the yellow luminescence typically observed in these flms, a property which has been found to be associated with the presence of oxygen in the GaN epilayer. ${ }^{23}$

A high-resolution reffection spectrum of the sample in Fig. 2 is showa in Fig. 3. In this experiment, we are performing straight reflection; bowever, the sample is off normal incidence by $\sim 15^{\circ}$ for reasons mentioned earlier. The $A$ and $B$ free excitons are observed to be at 3.486 and $3.497 \mathrm{eV}$, respectively. These values are in good agreement with the only other pubiished values for the energies for the A and $B$ bands in GaN crystals. ${ }^{.}$The small difference in energy $(\sim 3$ $m(V)$ in comparison to the values in Ref. 1 can be explained by differing amounts of residual stress present in the epitaxial GaN films due to their different thickness. The reflection spectrum in Fig. 3(b) shows the fllm to be of excellent uniformity and has been analyzed to determine that the GaN film thickness is $2.35 \pm 0.11 \mu \mathrm{m}$. This is $6.8 \%$ larger than the expected thickness of $2.2 \mu \mathrm{m}$ for this particular sample, and is the to limited accuracy of detemining the Ga fux using a bearn equivalent pressure, as well as drift in the Knudsen cell

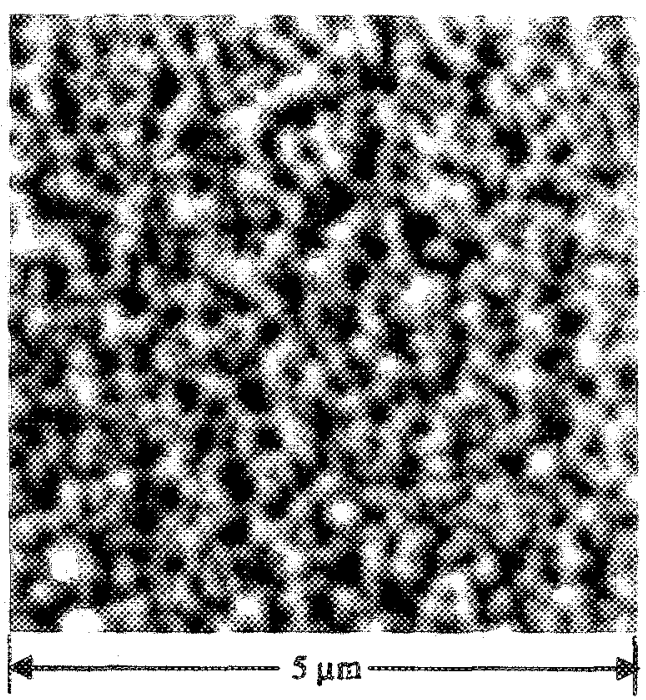

FG. 4. Atomic force microscope image of surface morphology of $2.0-\mu \mathrm{kn}$ thick GaN on a 200-A-thick AlN buffer on $\mathrm{Al}_{2} \mathrm{O}_{3}(0001)$. Black to white gray scale is 79 min.

Ga flux over the extended growth period. We belicve our rates to be accurate only to within $\pm 10 \%$ using this technique. It has not been possible to obtain RHEED oscillations for rate calbration due to the three-dimensional morphology of these firms.

The mompology of a 2.0 -km-thick GaN film is shown in Fig. 4. The $5 \mathrm{~km}$ square atomic force microscope image shown in Fig. 4 exhibits a surface roughness of $179 \AA$ as determined by asing the height difference correlation function. ${ }^{24}$ This relatively large surface roughness is typical of GaN fims grown by $\mathrm{MBE}$ under nitrogen rich growth conditions. ${ }^{20,25}$ We believe our GaN films to be nitrogen polar as determined by boh convergent beam electron diffraction measurements and by the higher etch rate in molken KOH in comparison to Ga polar GaN films grown by MOCVD. A mixed polarity GaN layer would also give these results, but such a layer would not exhibit the narrow FWHM of the Bragg scan shown in Fig. 1. Nitrogen polar GaN films grown by MBE have been observed by other groups using armmonia ${ }^{26}$ as well as nitrogen plasma ${ }^{27,28}$ as nitrogen sources.

Figure 5 is a seemingly anomalous result for silicon doping of otherwise typical GaN films grown by MBE. Figure 5 (a) shows the free electron concentration as a function of silicon Knudsen cell temperature for severa! silicon doped GaN (GaN:Si) calibration runs spanning an extensive time period during which the chamber "background" conditions varied considerably. The increase in free carriers for higher silicon cell temperature is as expected, but a lower limit of $-5 \times 10^{17} \mathrm{~cm}^{-3}$, occurring at a silicon Knudsen cell temperature of $T_{\mathrm{Si}} \sim 1250^{\circ} \mathrm{C}$ is observed. This is a factor of $\sim 10^{2}-10^{3}$ high in comparison to those of other III $-V$ compound semiconductors. For example, unintentionally doped GaAs grown by MBE is typically $p$ type with $n_{p}-3-5$ $\times 10^{14} \mathrm{~cm}^{-3}$. The room temperature thermally generated intrinsic carrier density should be $n_{i} \sim 10^{-11} \mathrm{~cm}^{-3}$, and hence, is not a contributing factor. Figure $5(b)$ shows the corre- 

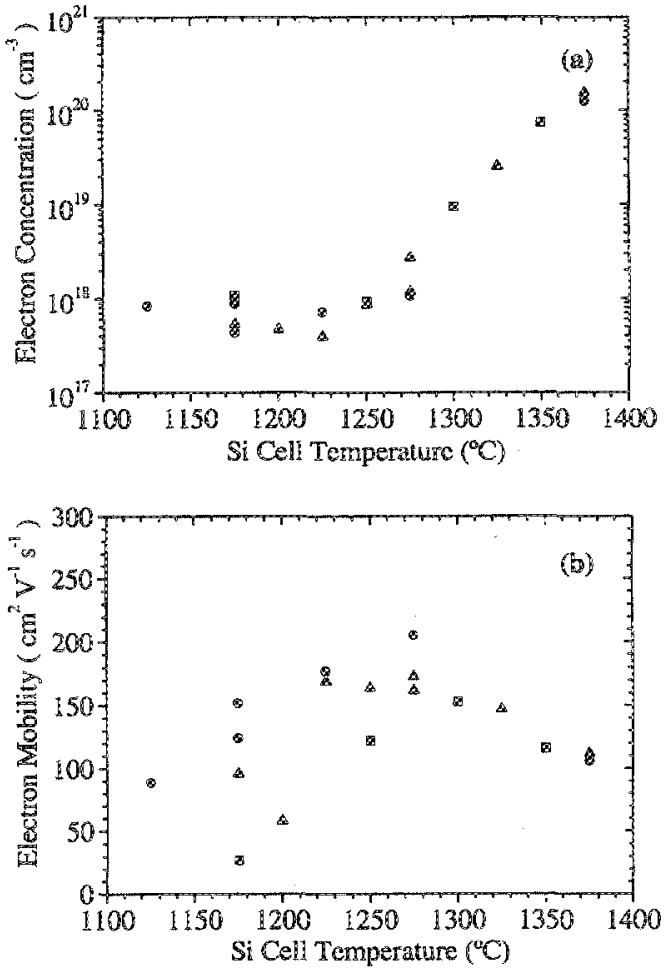

FIG. 5. (a) Free electron concentration and (b) corresponding electron mobility as a function of silicon Knudsen cell temperakure for a range of samples taken over an approximately 18 month period during which -300 growths were performed. Bifferent symboks reflect different growth periods between chamber openings.

sponding electron mobilities as a function of silicon cell temperature. At higher doping leveis, the mobility is observed to decrease in agreement with ionized impurity scattering theory. The mobility is observed to peak at -200 $\mathrm{cm}^{2} \mathrm{~V}^{-1} \mathrm{~s}^{-1}$ at $T_{\mathrm{Si}} \sim 1250^{\circ} \mathrm{C}$. This corresponds to an average dislocation density of $-10^{9} \mathrm{~cm}^{-2}$ according to recent work on the role of dislocation scattering in $n$-type GaN films. ${ }^{29,30}$ Below $T_{\mathrm{Si}} \sim 1250^{\circ} \mathrm{C}$, however, the mobility is seen to cecrease rapidly and exhibit considerable variation between samples with similar doping levels. This is again in contrast to typical $\mathrm{II}-\mathrm{V}$ doping where the room temperature electron mobility is observed to remain high ard relatively constant for $n$-type doping levels between $10^{14}$ and $10^{17} \mathrm{~cm}^{-3}$.

The reason for the anomalous transport properties of the GaN:Si films can be explained by the SIVS results shown in Fig. 6. Figure $6(a)$ is a SIMS profle of an uninientionally doped GaN film grown at $800^{\circ} \mathrm{C}$ on an AlN buffer on $\mathrm{Al}_{2} \mathrm{O}_{3}(0001)$. Beginning at the nitride/sapphire interface, both oxygen and aluminum can be seen to diffuse $\sim 1 \mathrm{wm}$ into the GaN film. This can only be due to dissociation of the sapphire itself as any surface source of these contaminants would continue throughout the film. Consider the pronile of the oxygen in the GaN. The concentration of oxygen appears constant for $\sim 0.5 \mathrm{sm}$ out from the nitride/sapphire interface, and then urops off at a rate that can be fit reasonably well with a complementary error function where the source concentration is constant. ${ }^{31.32}$ We believe the region of constant oxygen concentration is that of the solid solubility limit of oxygen in GaN at $800^{\circ} \mathrm{C}$. It is important to note that the Hall free electron concentration is considerably iess than the oxygen concentration, and hence, not all oxygen atoms are contributing free carricrs at room temperature. This may be due to the oxygen occupying a deep level in the band gap or possibly the result of some complex involving native defects and oxygen that traps carriers donated by the oxygen atoms. Regardless, the large magnitude of the oxygen concentration would certainly lead to a high degree of carrier scattering and a corresponding decrease in electron mobility. Figure $6(\mathrm{~b})$ is a SIMS profie of an unintentionally doped GaN film grown at the higher substrate temperature of $870^{\circ} \mathrm{C}$ on an $\mathrm{ANN}$ buffer on $\mathrm{Al}_{2} \mathrm{O}_{3}(000)$. Here, the oxygen and aluminum can be seen to diffuse across nearly the entire GaN him. This is consistent with an increase in diffusion rate due to an increase in substrate temperature. However, the oxygen profie is more nearly fit with an exponential decay. This could be due to the competing processes of the increased solubility limit of oxygen in GaN at this temperature, the increase in the oxygen diffusion rate, and the dissociation of the sapphire possibly only slightly increasing or remaining the same, or some combination of these effects.

Figure $6(\mathrm{c})$ is for GaN:Si at a level of $4 \times 10^{16} \mathrm{~cm}^{-3}$. This silicon doping level appears to slighty reduce the degree of diffusion of oxygen into the GaN. Figure 6(d) shows that a factor of 5 increase in the silicon concentration, to 2 $\times 10^{17} \mathrm{~cm}^{-3}$, results in a total elimination of the diffusion of oxygen into the GaN to within experimental error. We believe this is due to a formation of a strong $\mathrm{Si}-\mathrm{O}$ bond, and to a significantly reduced diffusion coefficient of the resulting Si-O complex. The silicon concentration of $2 \times 10^{17} \mathrm{~cm}^{-3}$ at $T_{\mathrm{si}}=1225^{\circ} \mathrm{C}$ corresponds well with the onset of the anonnalous transport properties shown in Fig. 5. Figure 6(e) shows that the outdiffusion from the sapphire substrate remains suppressed for a higher silicon doping level of $1 \times 10^{20}$ $\mathrm{cm}^{-3}$. The sight decrease in the silicon concentration as the growth proceded was found to be due to the silicon charge moving during the growth due to the downward facing configuration of the silicon dopant oven and the exceedirgly high operating temperature.

We find the dissociation of the sapphire substrate under the present MBE growth conditions surprising. However, we believe this effect to be independent of epitaxial deposition technique, and we expect the diffusion of oxygen into $\mathrm{GaN}$ films to be exacerbated for nitride growth techniques such as hydride vapor phase epitaxy or MOCVD where growth of GaN usually occurs $\sim 1050^{\circ} \mathrm{C}$. Because we believe oxygen auto doping of GaN on sapphire to be a serious problem for all nitride epitaxial techniques, we have investigated if there exists a similar problem for $\mathrm{GaN}$ on the alternative stbstrate material SiC. Figure $6(t)$ shows the STMS profle of unintentionally doped GaN on an AlN buffer on the $\$$ i face of SiC $(0001)$. Clearly, a very similar result is observed in comparison to Fig. 6(a). Both silicon and carbon are observed to diffuse ont approximately $1 \mu \mathrm{m}$ from the nitride/carbide interface. Also in Fig. $6(f)$ we observe the oxygen signa to be below the detection limit everywhere except at the nitride carbide interface. We believe this to be due to residual oxygen on the surface at the begirning of growth, as well as the 

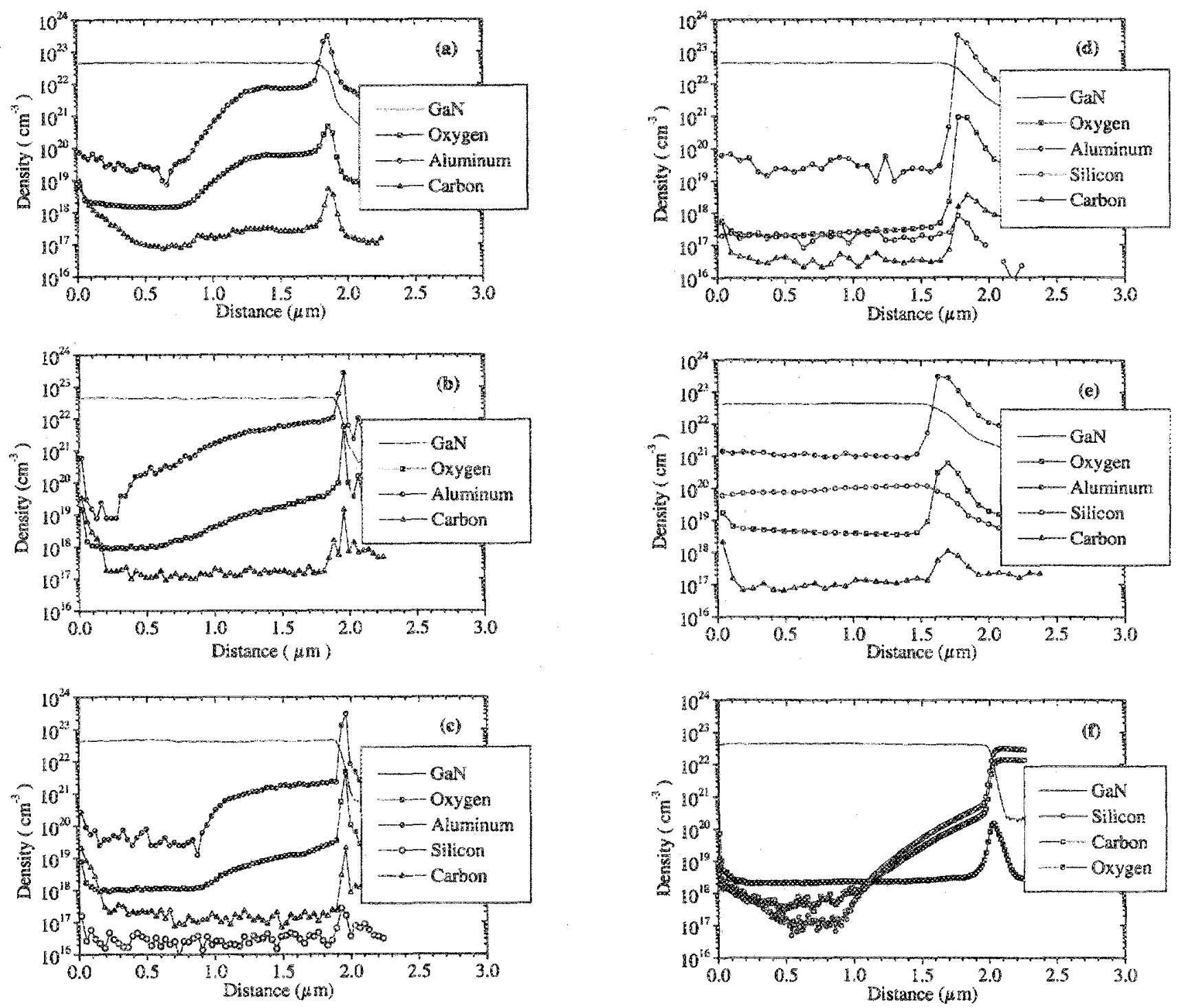

FIC. 6. SIMS results for unintentaly doped and silicon doped $\mathrm{GaN}$ samples. Figures (a) and (b) are for uaintentially doped GaN grown on $\mathrm{Al}_{2} \mathrm{O}_{3}(0001$ ) at (a) 800 and (b) $870^{\circ} \mathrm{C}$, respectively. Figures (c), (d), and (e) are for GaN:Si films grown on $\mathrm{Al}_{2} \mathrm{O}_{3}\left(000 \mathrm{~V}\right.$ ) with silicon doping concentrations of $4 \times 10^{16}$, 2 $\times 10^{17}$, and $1 \times 10^{20} \mathrm{~cm}^{-3}$, respectively, as deternined by SMMS. Figure (f) is for unintentially doped Gan grown on the $\mathrm{Si}$ face of $\mathrm{SiC}(0001)$.

oxygen gettering property of aluminum in the AIN buffer layer. The microstructure and photoluminescence properties (not shown) of this GaN on SiC is comparable to that shown in Figs. 1 and 2. We are unable to obtain transpont properties of the nitride epitaxy on $\mathrm{SiC}$ due to the conducting nature of the substrate. Semi-insulating on-axis $\mathrm{SiC}(0001)$ is cost prohibitive at this time.

From the resulss in Fig. 6 , we observe that modeling of the $\mathrm{GaN}$ as a single layer for transport analysis is appropriate only for GaN:Si films that have been heavily doped. However, for GaN films that are unintentionally doped or have been doped with silicon at a level less than $\sim 5$ $\times 10^{17} \mathrm{~cm}^{-3}$, transport analysis should employ a two layer conduction model consisting of a layer of essentially undoped, high mobility $\mathrm{GaN}$ over a layer of low mobility heavily oxygen doped $\mathrm{GaN}$ beginning at the $\mathrm{Al}_{2} \mathrm{O}_{3}(0001)$ interface and extending a considerable distance into the GaN film, a distance which depends on the MBE growth conditions. Further, the soltce of oxygen contamination of the
GaN is found to be dissociation of the sapphire. This is in contrast to the findings of Kim et al. ${ }^{14}$ who concluded that the oxygen contamination in their $\mathrm{MBE}$ GaN samples was due to oxygen irapurities in the ammonia gas. It is interesting to note that oxygen doping of the $G a N$ by dissociation of the sappinire is consistent with the work of Reynolds et al. ${ }^{23}$ who concluded the yellow luminescence from GaN is due to a complex involving intrinsic defects and oxygen, and the work of Gorlewski et al ${ }^{33}$ who observed a significant increase in yellow luminescence near the nitricie/sapphire interface.

\section{\$UMAARY}

Our results show that during the MBE growth of unintentionally doped GaN on sapphire, the sapphire substrate dissociates, and the stbsequeat aluminum and oxygen atoms diffuse a significant distance into the nitride film. We also show that silicon acts to suppress the diffusion of oxygen. 
We believe the rechanism responsible for suppression of oxyger diftusion is the formation of a stong $\mathrm{si}-\mathrm{O}$ bond, and a reduced diffusion coefficient of the subsequent Si-O complex. Blectrically, this is an n-type dopant suppressing another $n$-type dopant, and is primarily observable as a maximum in the electron mobility at the onset of rxygen outdiffusion from the sapphire. One topic that merits future investigation is to delta dope the AlN and/or GaN near the interface with an scceptor such as carbon, which is known to diffuse less than $\mathrm{Mg}$ or Be, for example. We attempted to do this using propane as the carbon source, but we did not achicve any measurable carbon incorporation in the $\mathrm{GaN}$ thin tim. Other groups ${ }^{34}$ have been successful in achieving carbon doping of GaN by other techiques and found the films to be hightly resistive. Carbon doping near the interface may suppress much of the effects of the dissociation of the sapphire and allows for investigation of the intrinsic electrical and optical properties of GaN.

\section{ACKNOWHEDGMERS}

The authors thank E. Taylor for his assistance with the MBD system and T. Cooper for his assistance with the Hall system. The authors also thank C. I. Huang for encouragement and support. Q.H. X., D. C. R., and D. C. L. were supported under USAF Contract No. F33615-95-C-1619.

D. C. Reynolds, D. C. Look, W. Kim, O. Aktas, A. Botchkarcv, A. Sut= vator, H. Morkoc, and D. N. Talwar, J. Appl. Phys. 84.594 (1996).

${ }^{2} \$$. Nakamura, T. Mukai, and M. Scnoh, Apph. 1hys. Lett. 68 , 1687 (1994).

"S. Nakawem, T. Mukai, and M. Senoh, Jpa. J. Appl. Phys., Part I 30 , (1991); 'T. Kawabata, T. Matsuda, and S. Koike, J. App1. Phys. 56, 2367 (1987); B. Goldenberg, J. D. Zook, and R. J. Umer, Appl. Phys. Lett. 62. 381 (1993).

${ }^{4}$ S. Nakamura, M. Senoh, S.-I. Magahama, N. Iwasa, T. Yamada, T. Mato sushita, H. Kiyoku, and Y. Sugimoto. Jpn. J. Appl. Phys., Part 2 35, L74 (1996).

${ }^{5}$ S. Nakamura, M. Senoh, S.-I. Magannama, N. Iwasa, T. Yamada, T. Matsushita, H. Kiyoku, and Y. Sugumoto, Appl. Phys. Ieft. 68,3269 (1996).

${ }^{6} Z$. Ean, S. N. Mohmmad, O. Ackas, A. Botchkarev, A. Salvador, and H. Morkoc, Appl. Phys. Iett. 6\%, 1229 (1996).
${ }^{7}$ A. J. Sierakowki and L. F. Eastman, J. Appl. Phys. 8 , 3398 (1999).

${ }^{8}$ I. P. Smorckkova et al. I. Appl. Phys. 86, 4520 (1999).

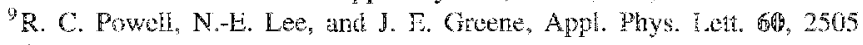
(1992).

${ }^{11}$ H. P. Maruska and J. J. Lietien, Appl. Phys. Lett. 15, 327 (1969).

II P. Perlin et ail., Fhys. Rev. Jet. 75, 296 (1995).

${ }^{12}$ D. W. Jenkins, I. D. Dow, and M.-H. Tsai, J. Appl. Inys. 72, 4130 (1992).

${ }^{13}$ B. Boguslawski, .: I.. Briggs, and J. Bernholc, Phys. Rev. B 51,17255 (1995).

${ }^{14}$ W. Kim, A. E. Botchkarev, A. Salvador, G. Popovici, H. Tang, and $H$. Morkoc, Appl. Phys. 82, 219 (1997).

15. Neugeburer and C. G. Van de Walle, Appl. Phys. Lett 6\%, 503 (1996).

lo W. Gotz, N. M. Johnson, C. Chen, H. Liv, C. Kuo, and W. Imler, Appl. I. Thys. Lett. $68,3144(1996)$.

${ }^{17}$ B.-C. Chung and M. Gershenzon, I. Appl. Phys. 72, 651 (1992).

${ }^{18}$ K. H. Ploog and O. Brandt, J. Vac. Sci. Technol. A 16,1699 (1998).

${ }^{19}$ K. C. $7 \mathrm{cng}$, J. Y. Lin, II. X. Jiang, A. Salvador, C. Popovici, H. Tang, W. Kim, and H. Morkoc, Appl. Phys. Lett. 71, 1368 (1997).

${ }^{20}$ J. F. Van Nostrand, R. L. Hengehold, K. D. Leedy, I. T. Gratt, I. R. Erown, and Q.-H. Xie, J. Appl. Phys. 86, 3120 (1999).

${ }^{21}$ F. A. Ponce, J. S. Major, Jro, W. E. Wlano, and D. F. Weké, Appl. Phys. Lett. 65,2302 (1994).

${ }_{22}^{2}$ A. K. Viswanath, J. I. I ee, S. Yu, D. Kim, Y. Choi, and C. Hong, J. Appl. Phys. 84, 3848 (1998).

23 D. C. Reynolds, D. C. Look, B. Logai, J. E. Van Nostrand, R. Jones, and J. Jenny, Solid State Commun. 1066,701 (1998).

${ }^{24}$ J. E. Vare Nostrand, S. J. Chey, and D. G. Cahill, Phys. Rev. 1357,12536 (1908).

${ }^{25}$ N. Grandjean, M. Leroux, J. Massies, M. Mesrine, and M. Lauge, Jpn. J. Appl. Phys., Part 138,618 (1999).

${ }^{26}$ R. Held et al. J. Appl. Phys. 85,7697 (1999).

${ }^{27}$ A. R. Snith, R. M. Feenstra, D. W. Greve, J. Neugehaur, and J. E. Northrup, Phys. Rev. Lett. 79, 3934 (1999).

${ }^{28}$ A. R. Smith, R. M. Foentra, D. W. Greve, M.-S. Shin, M. Skowronkki, J. Neigebauer, and 3. E. Northrup, Appl. Plys. Lett. 72, 2114 (1998).

297. C. Look amd I. R. Sizelove, Phys. Rev. Lett. \$2, 1237 (1999).

${ }^{30}$ N. C. Weimann, E. F. Fastman, D. Doppalaqudi, H. M. Ng, and T. D. Moustakas, J. Appl. Phys. 83, 3656 (1998).

${ }^{31}$ A. S. Grove, Physics and Techology of Semiconductor Devices (Wiley, New York, 1967), Chap. 3.

${ }^{32} \mathrm{~J}$. W. Mayer and S. S. Lath, Electronic Materials Sciense: For Inegrated Circuits in Si and GaAs (Macmillan, New York, 1990), Chap. 7.

${ }^{33}$ M. Godlewski, L. M. Goldys, M. R. Phillips, R. I.anger, and A. Barkki, Appl. Phys. Lett. 73, 3686 (1998).

${ }^{34}$ J. B. Webh, H. Tang, S. Rolfe, and J. A. Bardwell, Appl. Phys Lett. 75, $953(1999)$. 